\title{
A 'CERTIDÃO DE VIDA': UMA FERRAMENTA PARA TRABALHAR O LUTO EM SINGAPURA*
}

\author{
THE 'LIFE CERTIFICATE': A TOOL FOR GRIEF WORK IN SINGAPORE
}

RESUMO: Este artigo apresenta uma alternativa à formal e impessoal certidão de óbito - a 'Certidão de Vida', um documento narrativo terapêutico que presta homenagem às vidas daqueles que morreram. 0 artigo mostra exemplos de 'Certidões de Vida' utilizadas, assim como um mapa de seis etapas de prática narrativa que pode ser seguido simultaneamente, para ajudar a renegociar o relacionamento das pessoas com o luto.

PALAVRAS-CHAVE: terapia narrativa, luto, 'Certidão de Vida', morte, morrer, externalizar, documentos terapêuticos, testemunhas externas, cerimônia de definição, Conversas de re-member ${ }^{1}$.
ABSTRACT: This article proposes an alternative to the formal, impersonal document of the death certificate - a 'Life Certificate', a narrative therapeutic document to honour the lives of lost loved ones. The article shows examples of the 'Life Certificate' used in practice, as well as a sixstage map of narrative practice that can be used in conjunction with it, to help renegotiate people's relationships with grief.

KEYWORDS: narrative therapy, grief, 'Life Certificate', death, dying, externalising, therapeutic documents, outsider witnesses, definitional ceremony, re-membering conversations.

O uso de documentos é muito comum na terapia narrativa (Denborough, 2008; Epston, 1999; Freedman \& Combs, 1996; White \& Epston, 1990) para a apresentação do 'self' (White \& Epston, 1990). As práticas narrativas também incluem documentos terapêuticos no contexto da morte e do morrer (veja, por exemplo, Trudinger, 2009; White, 1997). Documentos de identidade formais tendem a ser impessoais, com 'fatos' impressos por uma autoridade diferente da pessoa cuja identidade é descrita. As práticas narrativas coletivas de David Denborough em Burma/Myanmar (Dulwich Centre Foundation International, International Women's Development Agency, \& Women's League of Burma, 2013) apresentaram novas maneiras de modificar os documentos de identificação formais para que sejam relevantes e gerem ressonância em quem trabalha com direitos humanos. Esses documentos de identidade preferida, situados dentro do domínio dos 'conhecimentos alternativos locais e populares' (White \& Epston, 1990), permitiram que os participantes se sentissem altamente envolvidos com sua noção de identidade e o tornar público habilidades e conhecimentos especiais.

Como um assistente social que atende pessoas sofrendo com luto, percebi como meus clientes eram impactados por histórias problemáticas envolvendo a dor de perder alguém querido, dificuldades envolvendo o 'deixar ir' as lembranças de quem faleceu, temas relacionados a 'assuntos pendentes', e lembranças perturbadoras dos eventos da perda. Essas histórias formavam os discursos dominantes do relacionamento das pessoas com o luto. Inspirado pelas ideias dos documentos de identidade preferida, procurei maneiras de usar uma do-

\begin{abstract}
* Nota da tradutora: Várias são as formas de traduzir esse termo: conversas de remembrança, conversas de re-associação, conversas de relembrança, entre outras. Essa dificuldade existe porque esse é um trocadilho com a palavra Remember que, em inglês, significa "lembrar". Porém, a mesma palavra pode ser decomposta em Remember, que significa 'voltar a ser membro'. Assim, as conversas de Remember são aquelas nas quais lembramos pessoas especiais em nossas vidas e definimos quais fazem ou voltarão a fazer parte do nosso clube da vida. Diante da dificuldade em encontrar uma palavra em português que traduza integralmente o trocadilho proposto por Michael White, manterei, neste artigo, o termo original.
\end{abstract}

Recebido em 16/03/2018 Aprovado em 28/01/2019 
cumentação criativa dentro de parâmetros culturalmente relevantes em Singapura. A 'Certidão de Vida' foi desenvolvida como um giro alternativo para a certidão de óbito formal emitida para as famílias após a morte de um de seus membros. Desenvolvi a 'Certidão de Vida' na esperança de identificar e tornar públicas as histórias da pessoa que se foi, tendo como base como as pessoas preferem se lembrar dela. A certidão não identifica apenas detalhes da pessoa amada, mas também facilita reflexões sobre como essa pessoa influenciou nossas vidas e nossos valores. De forma inversa, também investiga de que maneira nós as influenciamos.

Este artigo delineia o desenvolvimento da 'Certidão de Vida' e o website (www.life-certificate.com) é uma plataforma para a realização de novas histórias em cerimônias de definição (Myerhoff, 1982). Eu analiso a 'Certidão de Vida' como uma ferramenta possível de ser aplicada nas terapias do luto, e ilustro seu uso por meio de um estudo de caso de Ramlah (nome fictício). O artigo termina com a discussão de usos possíveis da "Certidão de Vida' em outros contextos.

\section{PERSPECTIVAS DOMINANTES ENVOLVENDO O TRABALHO COM LUTO EM SINGAPURA}

O discurso dominante sobre o trabalho com luto em Singapura segue a perspectiva de trabalhar com nossos clientes pelos estágios (Kubler-Ross, 1970) considerados como iguais em todas as experiências de luto (negação, raiva, negociação, depressão e aceitação). As limitações em descrever o luto como seguindo vários estágios é evidente quando verificamos com as pessoas as diversas experiências de luto, assim como os significados que elas dão a estas experiências. Quando esperamos que as pessoas vivendo o luto passem por uma sequência fixa de experiências, nós descartamos as respostas únicas/singulares que elas dão para a perda.

De forma similar, William Worden (2009) enfatiza quatro tarefas principais que devem ser cumpridas para que o luto seja finalizado com sucesso: aceitar a realidade da perda, processar a dor do luto, adaptar-se a um mundo sem a pessoa falecida, e encontrar uma conexão duradoura com a pessoa falecida ao mesmo tempo em que começa uma nova vida. Em sua abordagem, Worden postula a flexibilidade ao trabalhar com as respostas únicas e individualizadas que as pessoas têm em relação ao luto. Uma crítica a esse modelo é que processar a dor por meio de atividades que estimulam reviver a experiência pode ser potencialmente retraumatizante (White, 2006; Yuen, 2007). Somente como um exemplo de algo alternativo, a evitação pode ser entendida como uma estratégia para enfrentar o luto ou trauma (Linehan, 1993) e, como tal, pode requerer habilidades para ser mantida.

\section{MUDANDO PARA AS IDEIAS CONSTRUCIONISTAS SOCIAIS}

O luto está incorporado nas experiências culturais das pessoas. Em Singapura, culturas variadas convivem com diferentes práticas religiosas. O discurso cultural do Taoísmo Chinês valoriza o ato de chorar e as manifestações visíveis do sofrimento no funeral da pessoa falecida; já o 
discurso cultural muçulmano Malaio valoriza conter as emoções e o foco nas práticas de oração.

As crenças dominantes podem ser opressivas por levar as pessoas a obedecer a ideias 'normativas' do luto que podem não se encaixar com seus próprios pontos de vista. A relação de cada pessoa com a cultura e a religião é única diante da sua própria compreensão de mundo. Alguém da tradição cultural chinesa pode achar a prática dominante de demonstrar visivelmente seu sofrimento algo muito chamativo e sentir dor e angústia ao ser obrigado a mostrar sua emoção pela pessoa falecida. Por outro lado, uma pessoa da tradição cultural muçulmana malaia também pode sentir desconforto de não ser capaz de expressar suas emoções livremente. Os sistemas de crença são formulados dentro das interações sociais dos domínios do discurso cultural (Neimeyer, 1998). Além disso, as pessoas experimentam vários graus de conexão com as narrativas de suas vidas; algumas delas estão comprometidas com suas crenças e suas práticas, enquanto outras experimentam um distanciamento delas (Monk, Winslade, Crocket \& Epston, 1997). Isso claramente amplia a complexidade dos assuntos envolvendo cultura e luto.

$\mathrm{Na}$ medida em que a nossa compreensão do processo do luto entra nos domínios do construcionismo social, podemos considerar revisões nas crenças dominantes de 'seguir em frente' e 'deixar (a pessoa falecida) ir’ (Kubler-Ross, 1970). Neimeyer (1990) discutiu o processo do luto como uma reconstrução de significado com ênfase na experiência singular do luto. Isso envolve afastar-se do pressuposto de que um luto bem-sucedido requer 'deixar (a pessoa que faleceu) ir', e aproximar-se da identificação do papel potencialmente enriquecedor de manter laços simbólicos continuados com a pessoa que faleceu.

Esses sentimentos foram retransmitidos por Lorraine Hedtke (2003), que discutiu como as pessoas queridas que faleceram podem continuar a ter um papel crucial em nosso 'clube da vida'. Práticas de re-member representam ideias que nos distanciam da noção de deixar alguém ir, enquanto dão suporte a uma conexão simbólica continuada com a pessoa que faleceu. Essa conexão é respeitosa, uma vez que facilita um legado continuado da pessoa no contexto do trabalho com a morte (White, 1998; White \& Epston, 1992). O processo de re-member é o centro da elaboração da 'Certidão de Vida' como uma ferramenta no trabalho com o luto.

\section{DA CERTIDÃO DE ÓBITO À CERTIDÃO DE VIDA}

Em Singapura, as famílias recebem uma certidão de óbito da pessoa da família que morreu. Essas certidões, assim como os documentos de identidade, são impessoais e permanentes (ver Figura 1) ${ }^{1}$.
${ }^{1}$ Imagens retiradas do artigo
original. 
Figura 1: Certidão de óbito de Singapura

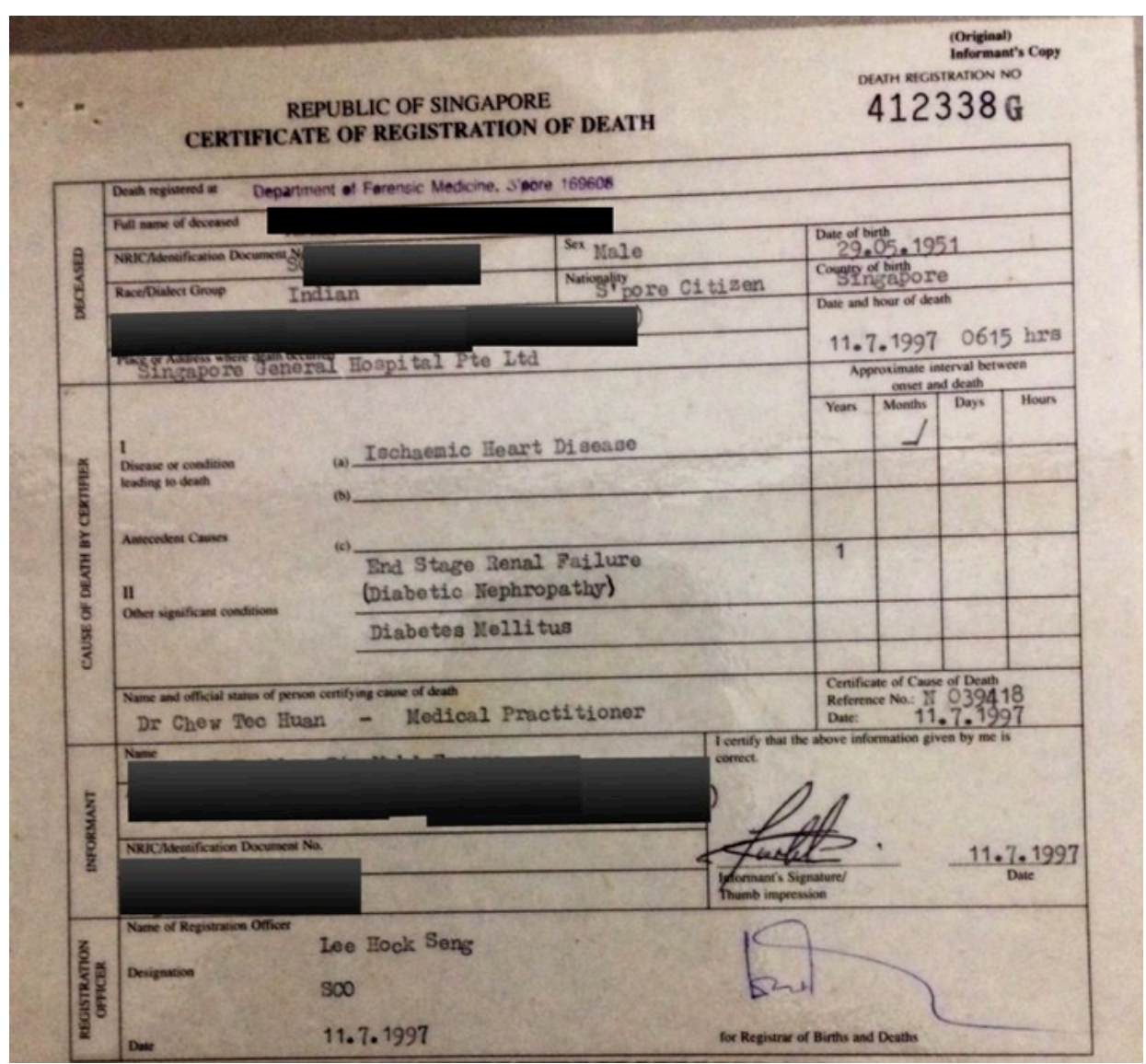

Contrastando com isso, a 'Certidão de Vida' é uma ferramenta que pode ser útil para identificar as histórias alternativas relativas às experiências de perda das pessoas. A certidão em si não é elaborada com base em componentes fixos, apesar de termos um modelo no website. Seus compo- nentes surgem de ideias gerais que podem auxiliar no desenvolvimento da segunda história. Portanto, deve ser algo flexível para que as pessoas façam uma 'Certidão de Vida' personalizada, que preste homenagem ao legado da pessoa querida que faleceu (ver Figuras 2 e 3 ). 
Figura 2: A 'Certidão de Vida'

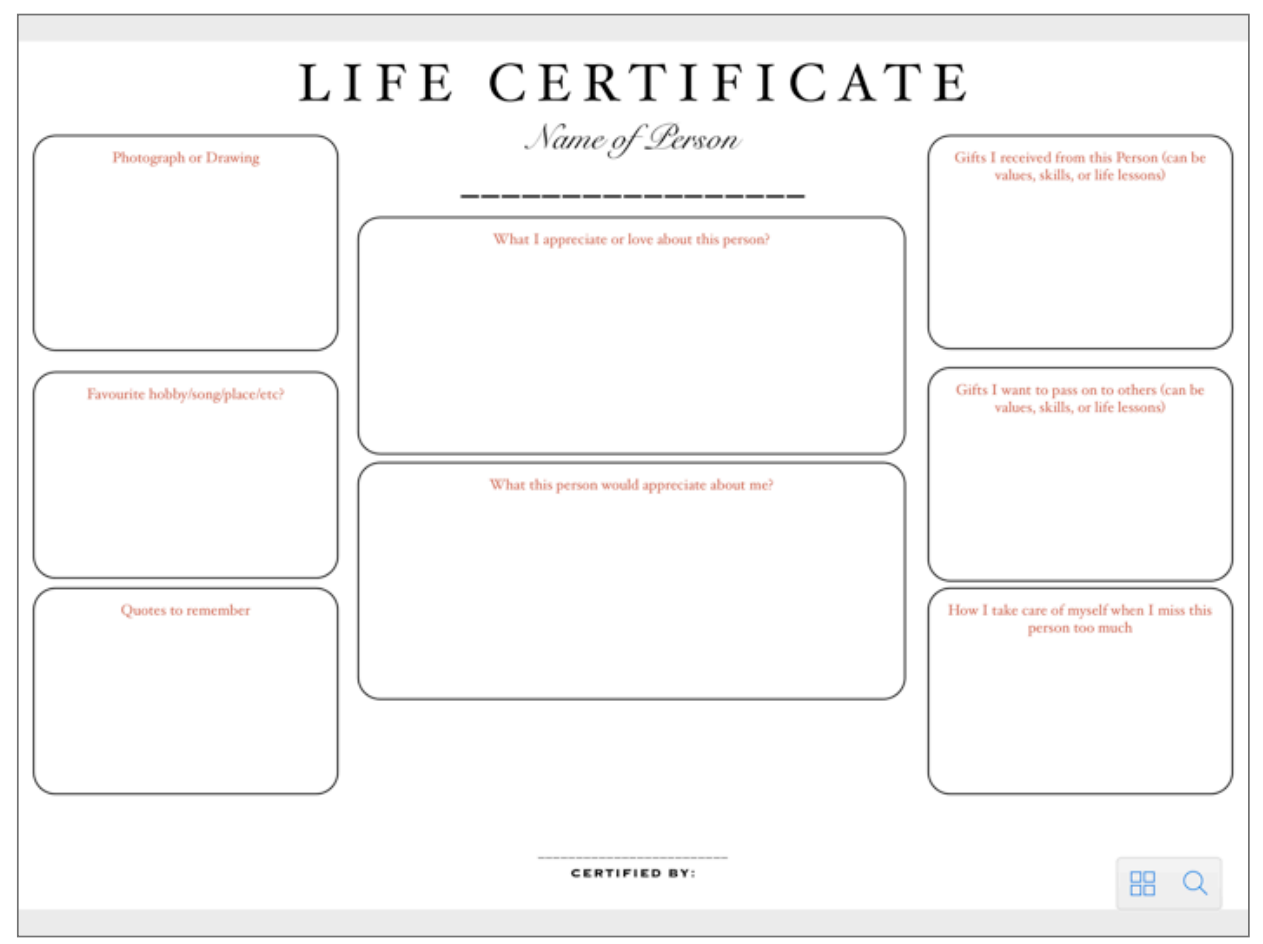

Figura 3: Exemplo de uma Certidão de Vida preenchida

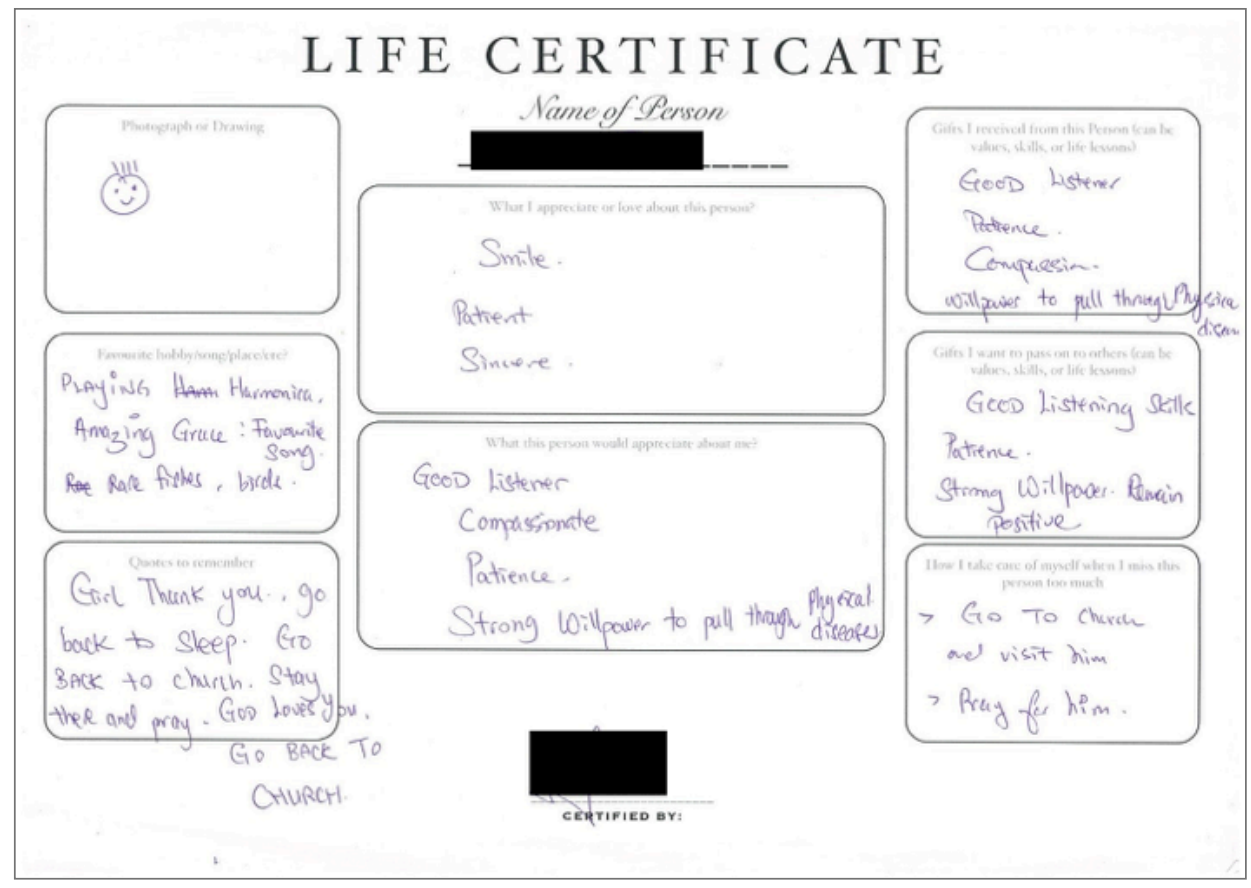

Nova Perspectiva Sistêmica, n. 63, p. 05-20, abril 2019. 
Geralmente, a 'Certidão de Vida' possui os seguintes elementos:

- Nome ou nome preferido da pessoa

- Fotografia ou desenho da pessoa

- Lazer; música; lugar favorito da pessoa

- Frases que a pessoa costumava dizer

- O que eu admirava e amava sobre/nessa pessoa

- O que essa pessoa admirava e amava em mim

- Presentes que recebi dessa pessoa (podem incluir valores, habilidades ou lições de vida)

- Presentes que eu quero passar para os outros (pode ser valores, habilidades ou lições de vida)

- Como eu cuido de mim quando sinto muita saudade dessa pessoa

- Assinatura e certificação do criador da certidão

A seguir, outras possibilidades de perguntas (se forem relevantes):

- Quais as lembranças que você tem dessa pessoa que contribuíram para você ser quem você é hoje?

- Quais lembranças você tem que valem a pena ser contadas de novo para homenagear essa pessoa?

- O que você gostaria de dizer para essa pessoa?

- O que essa pessoa teria para dizer sobre você?

A 'Certidão de Vida’ apresenta uma oportunidade para as pessoas enfrentando os assuntos sobre luto de recuperarem seu relacionamento com as pessoas queridas que faleceram. De acordo com Michael White, "conversas de re-member não são lembranças passivas, mas sim, reengajamentos deliberados com a história dos relacionamentos da pessoa com figuras significativas e com as identidades dela na vida presente e no futuro projetado" (2007, p.129). Ao utilizar a 'Certidão de Vida' junto com as conversas de re-member, podemos nos afastar das experiências de dor, de inutilidade e isolamento que podem estar relacionadas com as lembranças envolvendo a perda, e abraçar as lembranças e novas compreensões desses relacionamentos.

O desenvolvimento de histórias secundárias pode ser facilitado por meio dos seguintes mapas de averiguação:

- Falar sobre o falar sobre o luto

- Externalizar a experiência do luto e mapear seus efeitos na vida da pessoa lidando com o luto

- Reconhecer e homenagear as contribuições da pessoa falecida e apoiar a continuidade do legado dessa pessoa

- Verificar as contribuições da pessoa para a vida de quem faleceu

- Identificar e documentar as formas de lidar com o luto

- Envolver as considerações das testemunhas externas

\section{FALAR SOBRE 0 FALAR SOBRE 0 LUTO}

'Falar sobre o falar' é um conceito que já foi discutido por vários autores (Dallos, 2006; Fredman, 1997; Freedman \& Combs, 1996). Envolve o processo de discutir o que é ou não confortável de conversar durante as sessões, assim como vários entendimentos sobre o luto e seus efeitos. Falar sobre o falar sobre o luto garante a transparência da relação terapêutica, o que promove a colaboração. Isso envolve perguntas que convidam à discussão sobre o luto, assim como as expectativas de como o trabalho terapêutico pode ajudar: 
- Você acha que ajudaria se conversássemos sobre o que você está tendo que enfrentar nesse momento?

- Como você pensa que seria uma conversa bem-sucedida?

- Quais são suas expectativas com relação a essa conversa?

- Você conversou com mais alguém sobre esse assunto?

- Isso te ajudou/te atrapalhou?

- Você teria alguma ideia de onde essas conversas poderiam te levar?

Além disso, as seguintes perguntas são formas de investigar os pontos onde entendimentos culturais e pessoais sobre o luto se cruzam, e as histórias desses entendimentos. A primeira pergunta é uma adaptação do exercício de Glenda Fredman sobre indagar e elaborar histórias (1997):

- O que as suas crenças dizem sobre o que acontece quando:

- A pessoa morre?

- Depois que a pessoa morre?

- O que a sua cultura/religião falam sobre como você deve lidar com o luto (ou outra experiência próxima ao que chamamos luto)? Quais partes desse entendimento ajudam? Quais partes não ajudam?

- Quais são os entendimentos dos membros da sua família sobre como o luto (ou outra experiência próxima ao que chamamos luto) deve ser administrado ou suportado? Quais partes desse entendimento ajudam? Quais partes não ajudam?

- Qual é o seu próprio entendimento sobre como você deve administrar esse luto (ou outra experiência próxima ao que chamamos luto)?

- De que forma esses diferentes entendimentos revelam o que você valoriza? Qual a história desse valor?

- Se levarmos em consideração esses valores que você possui, o que poderia ser feito de diferente para homenagear esses valores e a pessoa que você perdeu?

- Quais são as expectativas culturais ou de gênero referentes a como você deve agir:

- Durante e após o funeral de alguém próximo?

- Ao viver o luto de alguém próximo?

- Essas expectativas lhes ajudaram?

- Como você entende que deve manter o relacionamento com uma pessoa que já faleceu?

\section{EXTERNALIZAR A EXPERIÊNCIA DO LUTO E MAPEAR OS SEUS EFEITOS NA VIDA DA PESSOA QUE LIDA COM $O$ LUTO}

As conversas de externalização (White, 2007; White \& Epston, 1990) são importantes para separar o problema da identidade da pessoa, ao mesmo tempo em que permitem mapear os efeitos dos problemas nas vidas das pessoas afetadas pelo luto. Samad, um membro masculino da comunidade malaia, descreveu seu luto como 'fikiranpedih' (pensamentos doloridos) que o incomodavam. Em oposição ao uso de uma nomenclatura estrangeira tal como 'luto complicado', o uso de nomes de experiência-próxima (Geertz, 1983) facilita uma compreensão conectada dos efeitos do problema externalizado na vida cotidiana. Termos que são próximos à experiência possibilitam discussões que se afastam do domínio do diagnóstico e da perspectiva médica, e se situam no mundo sociológico dos nossos clientes. 
- Que nome você dá a todas essas coisas que lhe incomodam?

- Em quais áreas da sua vida, te incomoda?

- Quais as suas esperanças sobre papel que desempenha em sua vida?

- Existem momentos nos quais não te incomoda tanto?

\section{RECONHECER E HOMENAGEAR AS CONTRIBUIÇÕES DA PESSOA FALECIDA, E APOIAR A CONTINUIDADE DO LEGADO DESSA PESSOA}

A 'Certidão de Vida' representa um empenho em direção a validar a existência da pessoa que faleceu. Ao documentar de forma criativa histórias alternativas que contrastam com a história dominante da perda da pessoa, podemos homenagear as contribuições dela. A construção de um legado tem duas bases de apoio: a primeira, as histórias preferidas sobre a pessoa são 'imortalizadas' no 'certificado'. E, a segunda, os valores, as competências e habilidades que foram ensinadas podem ser homenageadas por meio do documento, e pode-se planejar maneiras de que tais 'presentes' possam ter a garantia de vida longa.

Em minha prática, essa é a fase na qual eu começo a considerar a possibilidade de utilizar a 'Certidão de Vida' como uma espécie de 're-member' em relação à pessoa que faleceu:

- O que você ama ou aprecia nessa pessoa?

- Quais são os presentes que essa pessoa lhe deu? Por que esses presentes são importantes?

- Quais são as lembranças que você tem que lhe recordam do que você apreciava nessa pessoa?
- O que essa pessoa diria de quem você é?

- Qual conselho essa pessoa teria para você?

- Quais formas de você viver a sua vida demonstram que você ainda mantém vivo o legado dessa pessoa (alguns valores que você sustenta, alguns rituais que você pratica, e outros)?

\section{VERIFICAR AS CONTRIBUIÇÕES DA PESSOA PARA A VIDA DE QUEM FALECEU}

Essas perguntas são orientadas para identificar histórias alternativas de como a pessoa vivendo o luto contribuiu para a vida de quem faleceu. $\mathrm{O}$ terapeuta é incentivado a evidenciar detalhes de como essa contribuição pode ter moldado a percepção que a pessoa falecida tinha de si mesma. Isso representa um momento-chave da terapia no qual a pessoa é incentivada a pensar sobre histórias que ela não contaria se estivesse preocupada com a história dominante da perda e da dor. Essa categoria de perguntas abre espaço para histórias alternativas que fogem das experiências comuns sobre luto às quais estamos acostumados:

- O que essa pessoa admirava em você?

- O que essa pessoa diria sobre como você também contribuiu para a vida dela?

- Que diferença você pensa que essa contribuição fez na vida dessa pessoa?

\section{IDENTIFICAR E DOCUMENTAR AS FORMAS DE LIDAR COM 0 LUTO}

Esses questionamentos incluem outro grupo de perguntas que facili- 
tam o desenvolvimento significativo de uma segunda história na qual podemos examinar o agenciamento pessoal presente nas respostas ao luto, ao invés de somente investigar os efeitos do luto em si:

Sempre tem a história do trauma e suas consequências - as pessoas têm a chance de falar sobre suas experiências traumáticas, e elas recebem apoio para contar aquilo que não falaram antes. E também tem a história sobre a reação da pessoa ao trauma, que costuma ser pouco conhecida... é de importância vital entrar nessa trilha e ajudar a pessoa a ampliar esse conhecimento (White, 2006, p. 30)

Buscar conhecer as formas de reação também facilita identificar forças, capacidades, habilidades e valores (Denborough, 2008; Yuen, 2007) que ajudam a ampliar a história alternativa. Um material muito rico pode ser desenvolvido por meio de práticas que incluem utilizar nomes de experiência-próxima, rastrear as histórias e os legados de habilidades, investigar planos futuros para essas habilidades, assim como incorporá-las ao contexto das tradições coletivas e culturais:

- O que você faz quando as lembranças e os pensamentos ficam muito sofridos?

- Como você conseguiu superar essa dor [ou outro nome externalizado] até agora?

- O que funcionou para manter a dor distante?

- Há alguma lembrança à qual você recorre, que lhe conforta?

- Quem está ao seu lado, ajudando você a superar a dor?

- Se a dor viesse incomodar você novamente, quais estratégias seriam úteis e quais atrapalhariam?

- O que essa dor revela sobre aquilo que você valoriza?
- Qual nome você dá para esse valor, essa habilidade ou esse conhecimento?

- Qual a história desse valor, dessa habilidade ou desse conhecimento? Como você aprendeu isso? Quem lhe ensinou?

- De que forma esse valor, essa habilidade ou esse conhecimento está conectado às suas crenças religiosas e culturais?

- Como esse valor, essa habilidade ou esse conhecimento fazem a diferença na maneira como você gostaria de se ver no futuro?

\section{ENVOLVER AS CONSIDERAÇÕES DAS TESTEMUNHAS EXTERNAS E DAS CERIMÔNIAS DE DEFINIÇÃO USANDO A 'CERTIDÃO DE VIDA'}

Michael White (2007) explicou como indivíduos, nas cerimônias de definição, são capazes de fazer uma re-autoria das suas experiências através das lentes de outros membros da comunidade, e poderem ter suas identidades validadas e reconhecidas da forma como preferem. As cerimônias de definição capacitam os participantes a serem vistos segundo seus próprios critérios e, consequentemente, se tornarem 'visíveis' (Myerhoff, 1986). As cerimônias de definição têm como foco trazer à luz visões preferidas de si mesmo, o que inclui histórias de competência para superar problemas externalizados (Lobovits, Maisel \& Freeman, 1995). Ao mesmo tempo, há um efeito de empoderamento durante a criação de documentos que possibilita a contribuição e a ação social por parte do cliente. Dentro dessa perspectiva, os clientes com os quais trabalhamos tendem a compartilhar as histórias de suas identidades preferidas. A ação de contar e recontar serve 
para ampliar essas histórias preferidas e revigorar a identidade para superar os efeitos do luto.

O processo de facilitar a cerimônia de definição com a 'Certidão de Vida' pode incluir testemunhas externas que já possuem algum tipo de conexão anterior com o cliente. As práticas com testemunhas externas podem acontecer das seguintes formas:

- Pessoas ou famílias serem entrevistadas pelo terapeuta sobre o conteúdo da 'Certidão de Vida' diante das testemunhas externas.

- O terapeuta entrevista as testemunhas externas que observam e refletem sobre os conteúdos da 'Certidão de Vida' diante da pessoa ou da família. Nesse contexto, as considerações das testemunhas externas podem ser gravadas caso as pessoas e as famílias não estejam presentes.

- As respostas das testemunhas externas sobre a 'Certidão de Vida' podem ser postadas no blog www.life-certificate.com.

As cerimônias de definição também podem ser incorporadas a rituais já existentes na família e na comunidade (Denborough, 2008). Por exemplo, uma família muçulmana malaia de Singapura pode decidir criar de forma coletiva uma 'Certidão de Vida' da pessoa que faleceu durante a cerimônia que marca os 100 dias de falecimento. Uma família chinesa com a qual trabalhei decidiu completar a 'Certidão de Vida' de seu pai durante o aniversário de um ano de falecimento.

De acordo com as quatro categorias das cerimônias de definição - identificar palavras/expressões, descrever imagens, incorporar respostas e reconhecer o transporte (White, 2007) pode-se utilizar as seguintes perguntas na 'Certidão de Vida':
- Após ouvir as histórias surgidas a partir da 'Certidão de Vida', o que lhe chamou atenção? Quais expressões foram significativas para você?

- Quais imagens vêm à sua mente? Quais imagens você tem em relação à identidade da pessoa que criou essa certidão? O que você pensa que ele(a) valoriza ou considera-precioso?

- Como essas expressões e imagens se conectam com sua própria história? Quais lembranças da sua própria vida vieram à mente enquanto você lia a 'Certidão de Vida' e ouvia as histórias?

- De que forma você foi tocado pelo que leu e vivenciou? De que maneira ouvir essas histórias da 'Certidão de Vida' afetou a sua vida? Quais novas ideias você tem agora com relação à sua própria vida e sua identidade? Como isso afetou a compreensão da sua história pessoal? Quais novas ações você pretende incorporar à sua vida?

Com essas considerações em mente, vou discutir como a 'Certidão de Vida' pode ser aplicada no trabalho com o luto apresentando a seguir: o estudo de caso de Ramlah.

\section{ESTUDO DE CASO: RAMLAH}

Ramlah, uma mulher do grupo cultural muçulmano malaio, chegou ao Centro de Serviço à Família encaminhada pelo Hospital de Saúde Mental no qual ela foi diagnosticada com depressão clínica devido a 'assuntos relacionados ao luto complicado' envolvendo a morte de seu pai. A morte de seu pai, Said, coincidiu com o recente divórcio de seu marido. Quando foi 
encaminhada, Ramlah estava grávida de sete meses de seu segundo filho, o que contraindicava qualquer uso de medicação que os médicos gostariam de prescrever. Assim, ela foi encaminhada para o Centro de Serviço à Família para que pudesse 'processar suas emoções'. Durante a primeira entrevista, ficou claro que Ramlah não tinha condições de falar sobre o luto e o trauma que ela estava vivenciando. Ela não estava se alimentando direito, dormia menos de quatro horas por noite, e ainda tinha pensamentos suicidas. Havia uma necessidade de administrar a sua segurança e os membros da família vieram para fazer parte do plano de prevenção do suicídio.

\section{FALAR SOBRE 0 FALAR SOBRE 0 LUTO}

Foi somente na terceira sessão, quando Ramlah mencionou que estava preocupada com as necessidades básicas de sua família, que eu mencionei se poderíamos conversar sobre o que ela estava vivenciando com relação ao luto. Para criar o contexto dessa conversa, também tínhamos conversado anteriormente sobre suas esperanças e expectativas relativas ao relacionamento terapêutico, e se havia assuntos de que eu deveria passar por cima, por ser de um gênero e de uma classe diferente da dela (apesar de sermos do mesmo grupo cultural muçulmano malaio).

Ramlah conseguiu conversar sobre seus próprios conflitos com sua recente hospitalização. Ela sentia como se seus direitos como mulher tivessem sido retirados e ela fosse mais uma vez punida após as perdas que havia sofrido. Ela se sentiu desrespeitada pelos médicos ao ser considerada como uma pessoa com alto risco de cometer suicídio, quando o Islã especificamen- te proíbe que uma pessoa tire sua própria vida. Isso foi ampliado quando ela ouviu os médicos comentando que ela poderia vir a ferir seus filhos também, o que invalidou seu papel de mãe.

Depois de entender suas expectativas de ajuda e definir o que era confortável para ela abordar, Ramlah começou a falar sobre a culpa que vivenciou com a morte de seu pai. Por conta de problemas que estavam acontecendo entre ela e seu marido, ela sentia que não foi capaz de ajudar seu pai de forma mais efetiva quando ele estava nos estágios terminais de um câncer de intestino. Ao conversarmos sobre as compreensões culturais relativas ao luto e à superação da perda, Ramlah falou sobre sua crença de que a alma de seu pai estava em um lugar melhor, apesar de ela se sentir perseguida pela perasaan salah (erro ou culpa) que a incomodava todas as noites antes de dormir. Investigamos suas crenças sobre o que aconteceu com seu pai e sua alma quando ele morreu. Investigamos a relação dela com aspectos culturais e religiosos relacionados ao luto. Ramlah falou sobre como a perasaan salah intensificou durante os momentos de recitar orações antes do seu pai ser enterrado, porque ela não conseguia entender o árabe. Ela sentiu como se houvesse desapontado o seu pai por não conseguir ler os versos do Alcorão para ele. Para Ramlah, ser capaz de ler alguns versos para seu pai representava um ritual islâmico importante.

\section{EXTERNALIZAR A EXPERIÊNCIA DO LUTO, E MAPEAR SEUS EFEITOS NA VIDA DA PESSOA LIDANDO COM O LUTO}

Ao externalizar o nome de experiência-próxima da perasaan salah, pudemos começar a mapear os seus efeitos em Ramlah e avaliar a forma pela 
qual Ramlah se contrapunha a eles. Investigamos os momentos singulares de respostas de Ramlah à perasaan salah e começamos a comentar essas respostas. Ela falou sobre utilizar alguns versos religiosos específicos que incluíam a frase "todo sofrimento tem um alívio" em seu esforço para se contrapor à perasaan salah.

\section{RECONHECER E HOMENAGEAR AS CONTRIBUIÇÕES DA PESSOA FALECIDA, E APOIAR A CONTINUIDADE DO LEGADO DESSA PESSOA}

As conversas com Ramlah sobre o seu pai e as contribuições dele durante os muitos períodos de dificuldade na vida dela criaram a oportunidade para apresentar a 'Certidão de Vida'. Ela sentiu uma conexão imediata com a ideia, uma vez que sentia medo e ansiedade somente ao olhar a certidão de óbito do pai. A 'Certidão de Vida' trouxe a oportunidade para que ela participasse da criação do legado de seu pai. Ramlah também mencionou um provérbio malaio: 'Harimau mati meninggalkan belang, gajah mati meninggalkan gading, manusia mati meninggalkan nama'. Literalmente: 'Tigres morrem deixando suas listras, elefantes morrem deixando sua tromba, e os humanos morrem deixando seus nomes.' Para Ramlah, garantir que o nome do seu pai seja honrado envolve fazer com que saibam das suas boas ações e de como foi importante ele cuidar dela. Ela contou que, das três filhas de seu pai, ela era a favorita. Ramlah completou sua 'Certidão de Vida' com frases de seu pai, que incluem: 'Haja o que houver, não importa o quão difícil seja, temos que respirar e manter a calma', e, 'Volte-se para Deus cada vez que seu coração estiver doendo'. À medida que escrevia essas frases, ela demons- trava um sentimento de alívio, como se seu pai estivesse ali, falando com ela, enquanto ela vivenciava sua perda em meio a múltiplos assuntos que afetavam sua presente situação. Ela experimentou uma calma que supunha ter perdido nas dificuldades que passou com seu marido. Era essa calma que ela queria resgatar em sua vida como uma continuação do legado de seu pai e uma garantia de que os valores dele continuariam vivos na família. Falou sobre a importância da religião, algo que seu pai sempre reforçava, e sobre sentir a religião como um presente que ela gostaria de dar para seus filhos para garantir que eles não cometessem erros parecidos com os que ela cometera no passado.

\section{VERIFICAR AS CONTRIBUIÇÕES DA PESSOA PARA A VIDA DE QUEM FALECEU}

Apesar de Ramlah não se interessar muito em falar sobre as suas contribuições para a vida de seu pai, ela se surpreendeu com o que falou. Percebeu que seu pai valorizava o fato de ela ser a filha que regularmente tirava tempo para estar com ele e conversar. Ela era capaz de confiar em seu pai e ele se sentia reconhecido e conectado a ela, e conseguia ser 'como um amigo' para ela.

Seus valores de piedade filial, consideração pelo sentimento dos outros e responsabilidade também apareceram. Isso a ajudou a entender como a perasaan salah chegou: era uma resposta à violação do seu senso de responsabilidade para com seu pai. Ela conseguiu acessar novas maneiras de entender sua dor, já que, apesar de não estar ativamente envolvida no apoio ao seu pai em seus últimos dias, foi ela quem esteve ao seu lado durante a doença. 
Esse entendimento de suas habilidades e de como ela contribuiu para a vida de seu pai deu à Ramlah uma sensação de alívio e reduziu a influência do perasaan salah em sua vida.

\section{IDENTIFICAR E DOCUMENTAR AS FORMAS DE LIDAR COM O LUTO}

O processo de identificar as formas de lidar com o luto ocorreu ao longo do trabalho terapêutico. Sempre que conversávamos sobre histórias da dor do luto (ou perasaan salah) que ela vivenciou, eu usava a dupla-escuta (Denborough, 2008; White, 2004; Yuen, 2007) para ouvir como ela tinha conseguido superar aquilo. Quando preenchemos a 'Certidão de Vida', conseguimos identificar as seguintes respostas para a seção intitulada 'Como eu cuido de mim quando eu sinto muita saudade da pessoa':

- Eu choro, ao invés de me forçar a manter os sentimentos represados. É bom chorar algumas vezes.

- Eu pego uma foto de nós dois que tenho guardada dentro da bolsa.

- Eu recito a Sura Al Inshirah do Alcorão e lembro do verso: 'todo sofrimento tem um alívio'.

- Eu recito a Al Fateha (um verso do Alcorão) para ele todos os dias.

- Eu lembro que fiz o melhor para lhe dar apoio em seus últimos dias.

- Eu assisto a Pendekar Bujang Lapok, sua comédia clássica favorita, quando estou muito triste.

- Conto para meus filhos sobre os grandes feitos de seu avô.

Ao detalharmos essas respostas, também conseguimos levantar as habilidades e valores que Ramlah conseguia utilizar, e continuamos a investigação para entender as histórias dessas habilidades e desses valores, a fim de ampliarmos a história alternativa.

\section{ENVOLVER AS CONSIDERAÇÕES DAS TESTEMUNHAS EXTERNAS E DAS CERIMÔNIAS DE DEFINIÇÃO USANDO A 'CERTIDÃO DE VIDA'}

Como Ramlah não se animou com a ideia de colocar sua 'Certidão de Vida' on-line, nós gravamos o depoimento de três testemunhas externas que já tinham vivenciado a perda de alguém querido. Uma das testemunhas, Ali, um membro da comunidade muçulmana malaia, falou sobre como a piedade filial parecia algo importante para Ramlah. Ele disse que sentiu ressonância com esse valor já que ele acredita que a piedade filial pode ajudar os pais falecidos a expiar suas penas na outra vida. Ao mesmo tempo, ele sentiu uma grande vontade de ter o relacionamento tão próximo de Ramlah com seu pai como exemplo para aprimorar o seu relacionamento com sua mãe. Ali falou do quanto ele se distanciou da sua mãe depois da morte de seu pai, e como se sentiu motivado a se reconectar com ela.

Outra testemunha externa, Tracy, uma mulher da comunidade chinesa, conectou-se com os versos do Alcorão: 'todo sofrimento tem um alívio'. Ela falou sobre a morte de sua irmã, que aconteceu numa época em que seu marido tinha sido diagnosticado com câncer. Foi importante conseguir olhar para os momentos em que o alívio estava presente. Ela se motivou a reconectar com suas práticas religiosas para conseguir dar sentido às dificuldades que estava enfrentando.

Após assistir a essas gravações com as testemunhas externas recontando a história, Ramlah percebeu como sua 
história teve um impacto na vida de pessoas desconhecidas. Ela se sentiu solidária com essas pessoas ao perceber que a sua experiência de luto era similar à de outros. Disse que se sentiu fortalecida para compartilhar suas histórias com outras pessoas que estivessem enfrentando o luto. Ao mesmo tempo, sentiu-se tocada pela vontade do Ali de se reconectar com sua mãe. Ela sentiu que também se separou de sua mãe depois da morte de seu pai, e se inspirou no depoimento dele para dar os passos de reconexão com ela.

\section{CONSIDERAÇÕES FINAIS}

O exemplo de Ramlah nos mostra como a 'Certidão de Vida' pode ser utilizada no trabalho sobre o luto na terapia individual. De forma mais ampla, a 'Certidão de Vida' pode ser utilizada na terapia de família como um projeto coletivo de re-member e homenagem à memória da pessoa falecida. Na Singapura multicultural, com suas várias cerimônias e seus festivais religiosos e culturais, existe a possibilidade de a 'Certidão de Vida' ser utilizada em inúmeros rituais interculturais.

Eu também considero ser interessante utilizar a 'Certidão de Vida' em situações de luto ambíguo (Boss, 2000) nas situações em que crianças sentem a perda de um parente que está preso. É uma prática comum em Singapura que a pessoa responsável por cuidar da criança esconda dela o fato de que seu pai está preso.

${ }^{3}$ Ao saber que este artigo seria traduzido e publicado no Brasil, Mohamed Fareez mencionou: "ficaria muito feliz em saber como essas ideias seriam adaptadas e aplicadas em outros contextos" (comunicação pessoal, 2018). Para entrar em contato com ele, acessem o blog www.fareez.sg. Na terapia, a 'Certidão de Vida' também foi usada no trabalho com quem está morrendo, com conversas sobre como a pessoa quer que sua vida seja homenageada depois de sua morte.

Também existe a possibilidade de utilizar a 'Certidão de Vida' no con- texto de grupos de trabalho com luto e grupos de pessoas com doenças terminais. Porém, a 'Certidão de Vida' se modifica e é adaptada de acordo com a necessidade das pessoas com as quais trabalhamos, para que seja culturalmente ressonante com a sua vivência do luto. Existe a necessidade de pesquisas mais direcionadas a considerar a relevância da 'Certidão de Vida' para os diferentes grupos culturais em Singapura: as culturas malaia, chinesa e indiana. $\mathrm{O}$ estudo de Hassan e Mehta (2010) sobre a vivência do luto por jovens muçulmanos malaios de Singapura sugere que respostas orientadas para o espiritual podem ser uma estratégia relevante para manter o relacionamento com a pessoa que faleceu. Pode ser interessante desenvolver perguntas que investiguem o contexto espiritual para lidar com o luto na comunidade muçulmana malaia. Além disso, futuras pesquisas podem investigar o impacto da 'Certidão de Vida' e dos mapas de investigação sobre as vivências do luto.

Este artigo discutiu a utilidade da 'Certidão de Vida' como uma ferramenta no trabalho com o luto. Faz-se necessária uma responsabilidade ética que garanta que essa ferramenta seja culturalmente respeitosa e se encaixe nas vivências das pessoas que nos buscam. Espero que este artigo amplie as histórias alternativas na maneira como o trabalho com luto é desenvolvido em Singapura ${ }^{3}$.
* Este artigo foi originalmente publicado em The International Journal of Narrative Therapy and

Community Work, 2015, no 2 , www.dulwichcentre.com.au. 


\section{REFERÊNCIAS}

Boss, Pu (2000). Ambiguous loss: Learning to live with unresolved grief. London, England: Harvard University Press.

Dallos, R. (2006). Attachment narrative therapy: Integrating narrative, systemic and attachment therapies. Berkshire, England: Open University Press.

Denborough, D. (2008). Collective narrative practice: Responding to individuals, groups, and communities who have experienced trauma. Adelaide, Australia: Dulwich Centre Publications.

Dulwich Centre Foundation International, International Women's Development Agency, \& Women's League of Burma. (2013). Narrative responses to human rights abuses: Sustaining women workers and honouring the survival skills of women from Burma/Myanmar. Melbourne, Australia: International Women's Development Agency.

Epston, D. (1999). Co-research: The making of an alternate knowledge. In Dulwich Centre Publications (Eds.), Narrative therapy and community work; A conference collection (pp. 143-146). Adelaide, Australia: Dulwich Centre Publications.

Fredman, G. (1997). Death talk: Conversations with children and families. London, England: Karnac.

Freedman, J., \& Combs, G. (1996). Narrative therapy: The social construction of preferred realities. New York, NY: W. W. Norton.

Geertz, C. (1983). Local knowledge: Further essays in interpretive anthropology. New York, NY: Basic Books.

Hassan, M., \& Mehta, K. (2010). Grief Experience of Bereaved Malay/ Muslim Youths in Singapore: The spiritual dimension. The Interna- tional Journal of Children's Spirituality, 15, (1), 45-57.

Hedtke, L. (2003). The Origami of Remembering. International Journal of Narrative Therapy and Community Work, (4), 58-63.

Kubler-Ross, E: (1970). On death and dying. New York, NY: Macmillan.

Linehan, M. (1993). Cognitive-behavioral treatment of borderline personality disorder. New York, NY: The Guilford Press.

Lobovits, D. H., Maisel, R. L, \& Freeman, J. C. (1995). Public Practices: An ethic of circulation. In S. Friedman (Ed.), The reflecting team in action: Collaborative practice in family therapy (pp. 223-256). New York, NY: The Guilford Press.

Monk, G., Winslade, J., Crocket, Ka, \& Epston, D. (Eds.) (1997). Narrative therapy in practice: The archaeology of hope. San Francisco, CA: Jossey-Bass.

Myerhoff, B. (1982). Life History among the Elderly: Performance, visibility, and re- membering. In J. Ruby (Ed.), A crack in the mirror: Reflexive perspectives in anthropology (pp. 99-117). Philadelphia, PA: University of Philadelphia Press.

Myerhoff, B. (1986). 'Life Not Death in Venice': Its second life. In V. Turner \& E. Bruner (Eds.), The anthropology of experience (pp. 261-286). Chicago, IL: University of Illinois Press.

Neimeyer, R. (1998). Lessons of loss: A guide to coping. New York, NY: McGraw-Hill.

Neimeyer, R. (1999). Narrative Strategies in Grief Therapy. Journal of Constructivist Psychology, 12, (1), 65-85.

Trudinger, M. (2009). Remembering Joan: Re-membering practices as eulogies and memorials. International Journal of Narrative Therapy and Community Work, (1), 29-38. 
White, M. (1997). Narratives of therapists' lives. Adelaide, Australia: Dulwich Centre Publications.

White, M. (1998). Saying Hallo Again: The incorporation of the loss relationship in the resolution of grief. In C. White \& D. Denborough (Eds.), Introducing Narrative Therapy: A collection of practice based writings (pp. 17-32). Adelaide, Australia: Dulwich Centre Publications.

White, M. (2004). Narrative practice and exotic lives: Resurrecting diversity in everyday life. Adelaide, Australia: Dulwich Centre Publications.

White, M. (2006). Working With People who are Suffering the Consequences of Multiple Trauma: A narrative perspective. In D. Denborough (Ed.), Trauma: Narrative responses to traumatic experience (pp. 25-85). Adelaide, Australia: Dulwich Centre Publications. (Reprinted from International Journal of Narrative Therapy and Community Work, 2004 (1), 45-76.)

White, M. (2007). Maps of narrative practice. New York, NY: W. W. Norton.

White, M., \& Epston, D. (1990). Narrative means to therapeutic ends. New York: W. W. Norton.

White, M., \& Epston, D. (1992). A Conversation about AIDS and Dying. In M. White \& D. Epston, Experience contradiction, narrative \& imagination: Selected papers of David Epston \& Michael White, 1989-1991 (chapter 2). Adelaide, Australia: Dulwich Centre Publications. First published in the 1991 No. 2 issue of the Dulwich Centre Newlsetter.

Wingard, B. (2001). Finding Our Own Ways to Grieve, to Remember and to Heal. In B. Wingard \& J. Lester
(Eds.), Telling our stories in ways that make us stronger (pp. 41-44). Adelaide, Australia: Dulwich Centre Publications.

Worden, W. (2009). Grief counseling and grief therapy: A handbook for the mental health practitioner (4th ed.). New York, NY: Springer.

Yuen, A. (2007). Discovering Children's Responses to Trauma: A responsebased narrative practice. International Journal of NarrativeTherapy and Community work, (4), 3-18.

\section{MOHAMED FAREEZ}

É assistente social na ensolarada Ilha de Singapura, onde ele atualmente é o chefe do Centro de Serviços da Família Cheng San (AMKFSC Serviços Comunitários Ltda.). Em seu trabalho, está interessado em desenvolver formas de integrar as ideias narrativas à gestão de projetos no serviço social e no trabalho comunitário em Singapura. Fareez também trabalha com pessoas impactadas pelo luto e a perda, nas quais ele valoriza as ideias de 're-member' como contra-histórias importantes ao discurso dominante do trabalho com luto. Fareez escreve sobre essa experiência como assistente social em seu blog www.fareez.sg, também uma maneira de entrar em contato com ele. 